\title{
Diary of an intestinal operation
}

\author{
SELLIS
}

$\mathrm{T}$ ODAY I SAW MY SPECIALIST ABOUT AN INCREASINGLY troublesome flare-up of Crohn's disease. It has been a year now since I was started on high doses of medication to try and control the cramping and diarrhea resulting from intense ulceration in my large intestine. My specialist thinks it is time to try surgery - a resection, which basically means cutting out the ulcerated section and sewing the ends back together. I feel a bit apprehensive about the surgery, but am willing to try it given that I will probably have an improvement in living quality once it is done. Surgery is scheduled as soon as possible (next week) and I spoke with the surgeon about the surgical procedure.

\section{PRE-OP THREE DAYS}

Monday: I was admitted to the hospital this morning, two days before they operate because first they want to do some tests to make sure that my ulcers have not spread. A pretty boring day, except that I had to drink $2 \mathrm{~L}$ of 'bowel prep' to clean out my intestine for the testing. Tastes like seawater, and even sucking a lemon between glasses doesn't help much. Luckily my room (a four bed ward) has its own toilet, and by bedtime I'm all 'cleaned out'.

Tuesday: They came for me early this morning for my colonoscopy. I asked to be given a tranquilizer first, as I find this test quite distressing. Luckily the painkillers they gave me were enough to ease my discomfort, and I even got to see the ulcerated section of my gut on the television screen as the fibreoptic tube travelled up my colon. Good news - the ulcers are confined to one distinct region. The rest of today I have spent resting. I'm not allowed solid food as I have another test tomorrow.

Wednesday: A further test - this time a barium meal to check out my small intestine. I don't mind this test too much - the taste of the barium mixture that you have to drink is bearable, and apart from that it is just like having an $\mathrm{x}$-ray. Unfortunately I have to have the barium cleaned out of my system because

This article was written by a patient with Crohn's disease undergoing surgery, and was submitted by Dr CN Williams. It is the hope of The Canadian Journal of Gastroenterology that readers will find this written record of a patient's personal experience both enlightening and thought-provoking. of the operation tomorrow - another $2 \mathrm{~L}$ of the horrible bowel prep! The anesthetist visited me to check for possible problems or allergies, and I also signed a consent form for my surgeon.

\section{OPERATION DAY}

My operation was scheduled for early afternoon, and much to my surprise there were no delays ( I know of one lady who had to wait an extra week because a more urgent case came up). I was nervous, but just wanted to get it over with. After dressing in the 'johnny shirt' and being given an initial dose of morphine, I was wheeled up to the operating room. The nurses were friendly and encouraging. A needle was jabbed in my arm, and soon I was fast asleep. I woke up this evening, to hear that the operation was successful. I'm pretty dozy, and have a catheter draining my urine, so at least I don't have to get up! It doesn't hurt too much because of the drugs. The nurses are keeping a close eye on me, and encouraging me to get up as soon as I can because of the danger of blood clots if I stay horizontal for too long. But turning sideways does hurt a lot right now. I have an IV in my left arm keeping me topped up with fluids.

\section{POST-OP FIRST WEEK}

Friday: This morning I managed to get up to sit in a chair while the nurse made my bed! I feel really weak, but the drugs are still keeping my pain under control, so I'm spending a lot of time sleeping. They are going to remove my catheter later today.

Saturday: Today is the first day that I feel properly awake. I have examined my scar - it is long and vertical, but neat. The scar is held together with staples - I feel a little like Frankenstein's monster! I have a horribly dry mouth still; which apparently is normal. But I am not allowed to drink anything until my intestine starts working again (by passing gas). Maybe tomorrow.

Sunday: I went for a little walk this morning down the corridor, holding onto the IV pole for support. Otherwise a pretty boring day.

Monday: Last night I passed some gas. I never thought I would be so glad to fart in my life! So now I can drink water, and they are putting me on the clear liquids menu. It's boring (lots of jello) but better than nothing, and it also means that the 
IV can be removed. I took my first shower with plastic wrap over my scar. The surgeon visited me today, and seems pleased with my progress.

Tuesday: I need less and less painkillers now, although I am getting some pain from food moving through my gut $-\mathrm{I}$ am told it will take a little while for things to settle down. I passed some stools this morning - they were only semi-formed, but the nurse assures me that it often takes a week for the intestine to start absorbing water properly again, so diarrhea is quite normal at this stage. I already feel relief from the cramps and pain that accompanied my Crohn's disease. I intend to go for a longer walk later today, to get my circulation going and keep my legs strong. Tonight I am going on a 'soft' solid diet - real food at last!

Wednesday: I am enjoying solid food, although I still have some areas of pain in my intestine as stools pass through. Defecating feels really funny as the muscles used to eject stools are not yet properly under my control. But otherwise I feel good, and the pain is much diminished.

Thursday: I was supposed to go home this morning but suddenly developed a high temperature and diarrhea. The doctors aren't sure what is causing it but are doing tests. I feel rotten, but at least I'm in the right place to get good care!

\section{POST-OP SECOND WEEK}

The infection dragged on for a few days, and seems to have been caused by an overgrowth of a bacteria in my gut. Unfortunately I have developed another complication, this time intense pausea and vomiting from a blockage in my small intestine, as shown by a second barium meal. I can't keep anything down and have had to be put on PPN (peripheral parenteral nutrition). I have also got a nasal-gastric tube going down into my stomach to pump out the bile and stop me from vomiting. It feels uncomfortable, but better than being sick! The surgeon is keeping an eye on me, and if the obstruction doesn't clear by itself he will re-operate, but he is obviously reluctant to do so because of the short time interval since my first operation.

\section{RE-OPERATION}

The obstruction partially cleared, but I still felt very nauseous, so on Friday I was re-operated. This time the operation was much shorter, and the problem was easy to fix: my small intestine had spilled out through a small hole in my mesentery, left there after the previous surgery. I am relieved that the obstruction has been fixed, and determined to quickly get better, although I am a lot weaker than after my last surgery and my muscles are more atrophied.

\section{DISCHARGE}

Friday: I went home today! This morning the staples were removed (it didn't hurt, surprisingly). I was amazed at how tough it was climbing the stairs to my apartment, and aim to take things very easy for a while until I get my strength back. I find that standing for any prolonged period makes me very tired, and I tend to hunch over in a stoop, I guess because my stomach muscles are weak and not supporting my back. I'm off all my Crohn's disease medication except for prednisone, a corticosteroid, because this must be reduced gradually over a series of weeks.

Saturday: I didn't sleep well last night, adjusting to a new bed and routine. Today I went to the park and managed to walk for half an hour - but was I tired afterward! It's good to be living with somebody who can take care of me, because I'm too weak to stand in a kitchen and cook right now. My appetite has not come back yet, and I can only eat small meals, but I'm told this is a normal response after surgery. I'm experiencing some wheeziness because it still hurts to cough.

\section{POST-OP TWO WEEKS}

My scar is healing well, and apart from itching it no longer hurts. My gut has also settled down and the indigestion has gone. I am passing solid stools now, much better than before the operation, and $\mathrm{I}$ am cautiously extending the range of foods I eat to fruits and more fibrous things. However, my leg strength is still not back to normal (those stairs still challenge me) and my back still bothers me a little. At least I'm no longer wheezing!

\section{POST-OP THREE WEEKS}

This week my body finally started to feel normal. I can walk for quite a while now, and yesterday I went swimming for the first time and managed 10 laps! My stomach muscles are getting stronger, and I can eat most foods now (though I haven't dared to try any curry or alcohol yet!). All in all, I feel the operation was definitely worth it, as I have no Crohn's symptoms and only two to three bowel movements a day. It will be good to be off steroids and get rid of the puffy face and acne, though I have to take the reduction very slowly from now on.

\section{POSTSCRIPT}

I continue to improve and will go back to work this week, a month after my second operation. I feel very positive about the immediate future, although there is always a danger of recurrence with Crohn's disease. To anyone contemplating surgery, I would say: consider your options and condition carefully, and if surgery promises a pain reduced, better way of life, then go for it! But remember to leave enough free time for recovery afterward, especially as unforeseen complications may make your stay in hospital longer than anticipated, as I found out (although I am still glad I had the surgery). Once again, I wish you luck! 


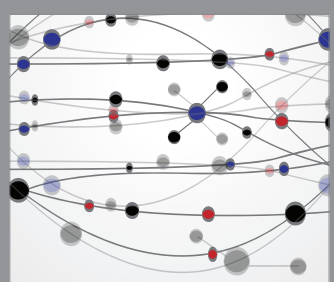

The Scientific World Journal
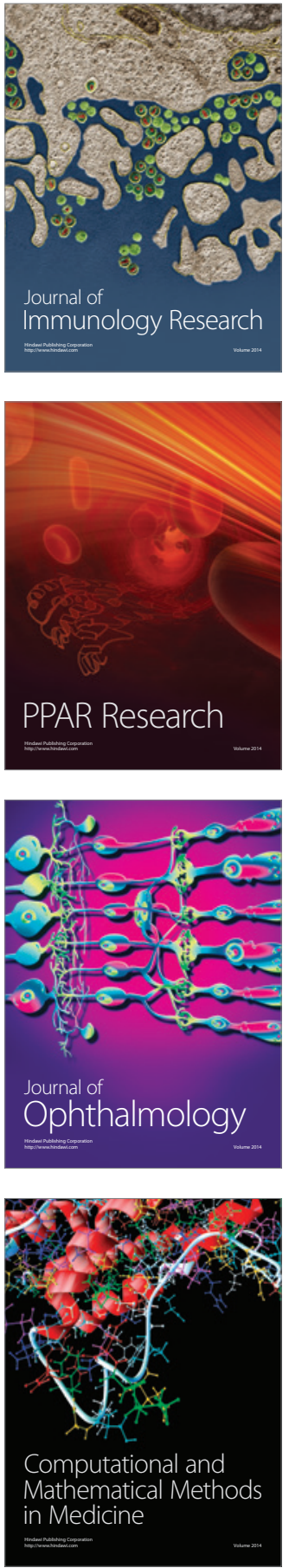

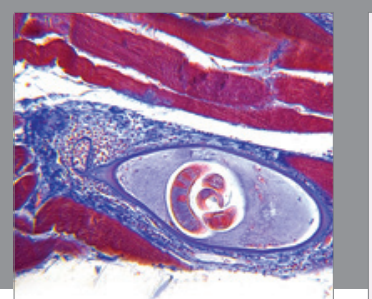

Gastroenterology Research and Practice

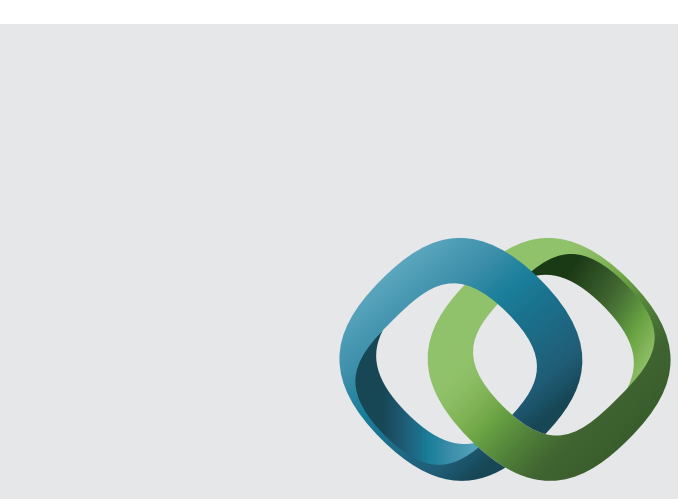

\section{Hindawi}

Submit your manuscripts at

http://www.hindawi.com
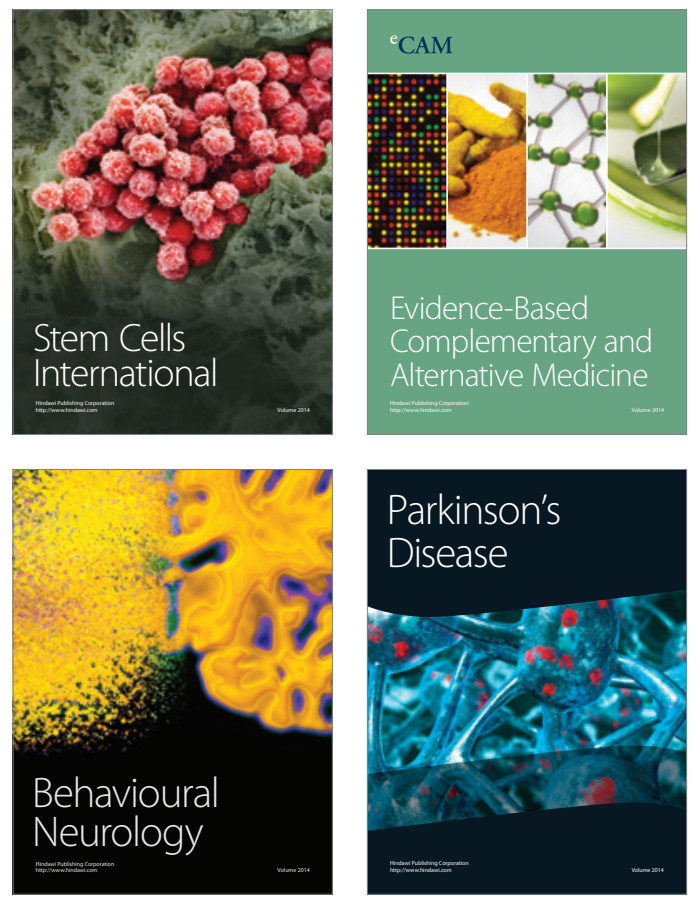
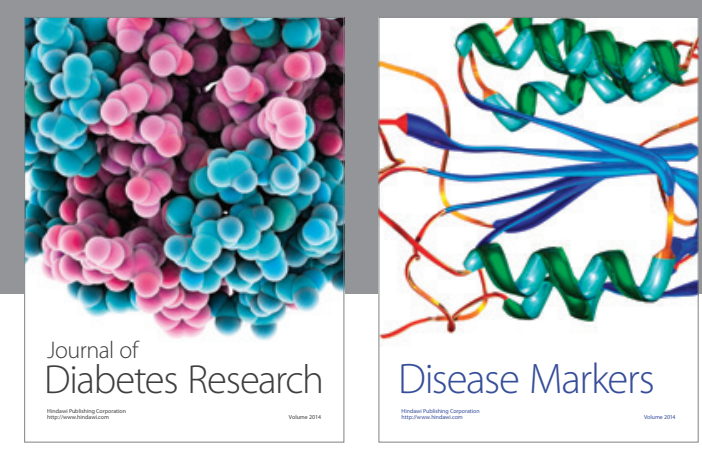

Disease Markers
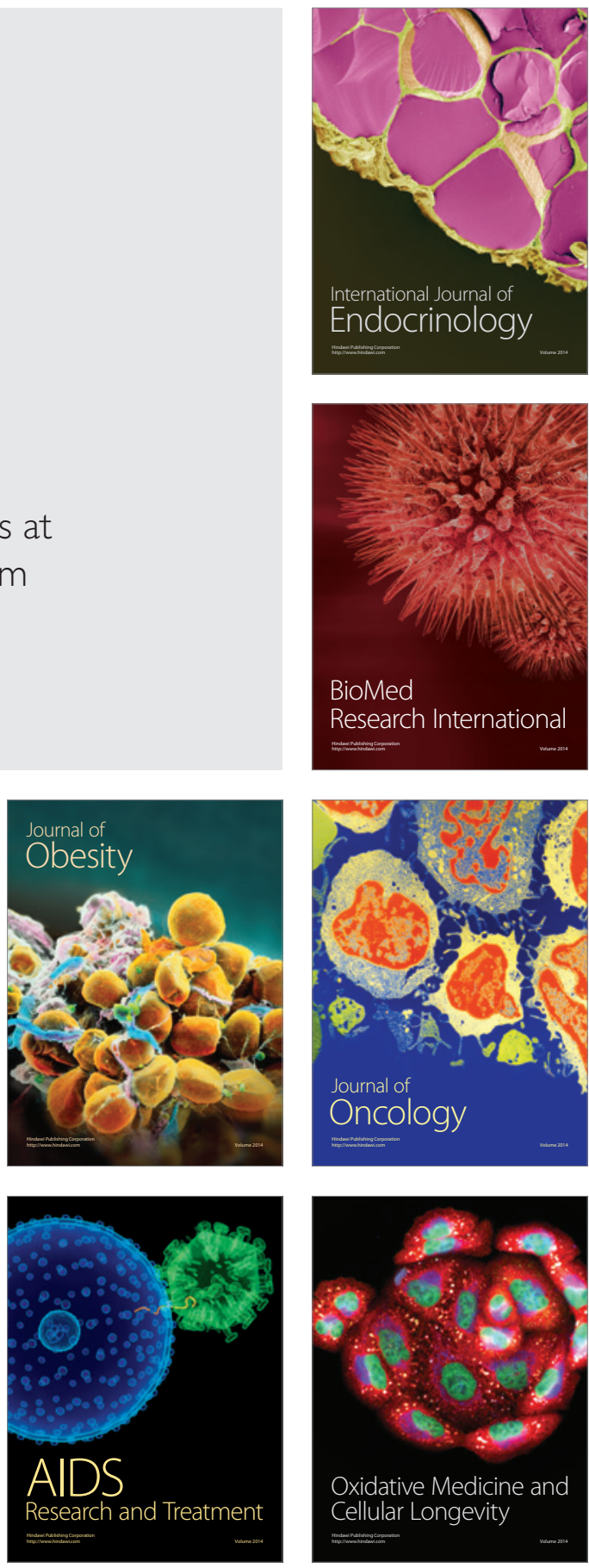